\title{
Gastric Calcifying Fibrous Tumor: A Clinicopathologic Analysis of 2 Cases
}

\author{
Wei Zhao* and Zhao Li Li \\ Department of Pathology, China
}

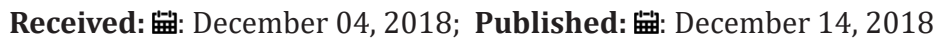

*Corresponding author: Wei Zhao, Department of Pathology, China

\begin{abstract}
Calcifying fibrous tumor (CFT) is a rare benign mesenchymal tumor which shows a predilection for soft tissue and the abdominal cavity. CFT usually affected children and young adults. To date only twenty cases of CFTS have been reported in the literature confined to the stomach. We presented here two cases of gastric CFTS. One patient was 55-year-old man and the other was 56-year-old woman. The two patients presents with slight upper abdominal pain and dyspepsia. The two tumors both originated in the gastric body and gastric endoscopy revealed polypoid submucosal masses, covered by an intact mucosa. Both of the patients accepted a wedge resection of the stomach. Histology was typical with uniformly hypocellular coarse collagen, lymphoplasmacytic infiltrates and psammomatous calcifications. Immunohistochemically, the tumor cells were positive for vimentin and negative for CD117, CD34, DOG-1, S100, smooth muscle actin, desmin and ALK1.The two patients with available follow-up had no evidence of recurrence at 19 and 24 months.
\end{abstract}

Keywords: Stomach; Calcifying Fibrous Tumor; Gastrointestinal Stromal Tumors

Abbreviations: CFT: Calcifying Fibrous Tumor; SMA: Smooth Muscle Actin; ALK: Anaplastic Lymphoma Kinase; GIST: Gastrointestinal Stromal Tumors; IMT: Inflammatory Myofibroblastic Tumor

\section{Introduction}

Calcifying fibrous tumor (CFT) is a rare benign mesenchymal tumor originally described by Rosenthal and Abdul-Karim as childhood fibrous tumor in two girls [1]. CFT was initially thought to be a reactive lesion resulting from tissue healing. However, recent studies demonstrated CFT is a real tumor with a tendency for local recurrence [2]. CFT of the stomach is quite rare [3-5]. Herein we present two cases of stomach CFTs and analyzed the clinicopathologic features of them. In additional, we reviewed the literature and differential diagnosis.

\section{Case Report}

\section{Case 1}

A 55-year-old man came to our hospital complaining of dyspepsia and slight upper abdominal pain from half a month ago. Physical examination and laboratory findings were normal. The patient underwent an endoscopic examination and revealed a submucosal mass at the greater curvature of the gastric body (Figure 1). Computed tomography scan demonstrated a well-circumscribed and homogeneous round mass at the great curvature of the gastric body. Then the patient accepted laparoscopic wedge resection of the gastric body. Macroscopically, the tumor was covered by intact mucosa and well-defined, measuring $1.5 \times 1.0 \mathrm{~cm}$. The cut surface was white to yellow. Microscopically, the tumor was well circumscribed, but non encapsulated. The tumor was surrounded by a peripheral cuff of lymphoid aggregates. Tumors were composed of characteristic hypocellular sclerosis with storiform coarse collagen and scattered inflammatory infiltrates composed predominantly of plasma cells and lymphocytes. Psammomatous calcifications was found in the tumor. The spindle cells were positive for vimentin and negative for CD117, CD34, S100, smooth muscle actin (SMA), desmin and anaplastic lymphoma kinase (ALK). The patient with follow up had no evidence of recurrence after 9 months.

\section{Case 2}

A 59-year-old woman was admitted to our hospital and gastroscopy revealed a mass in the gastric body. A wedge resection of the stomach body was performed. Gross examination revealed a well-defined solid mass with overlying gastric mucosa, measuring $1.2 \times 0.7 \mathrm{~cm}$. The cut surface was firm and white-yellow. Histologically and immunohistochemically, the manifestation of the tumor was similar to that of the case 1 . The patient with follow up had no evidence of recurrence after 14 months. 


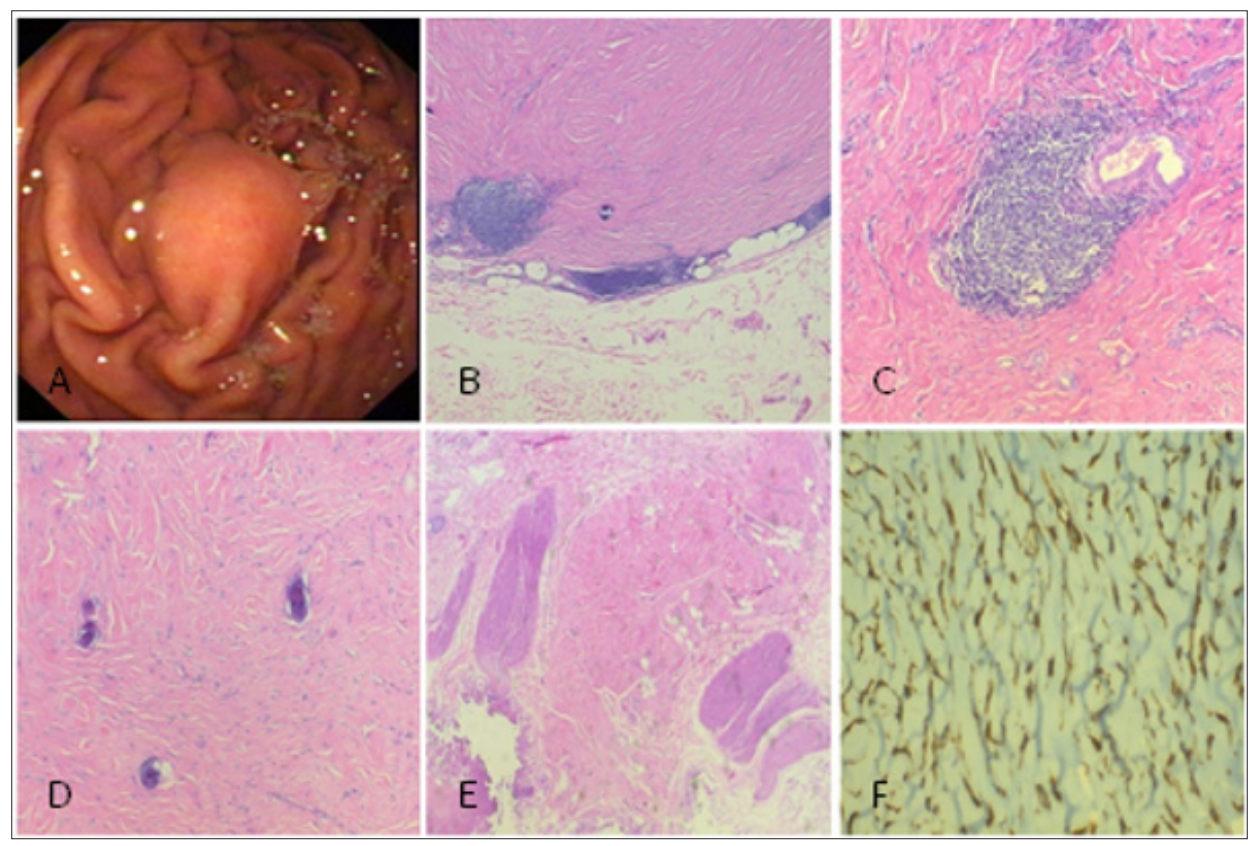

Figure 1:

A. Endoscopic examination revealed the polypoid submucosal mass in the greater curvature of the gastric body (case 1).

B. Peripheral lymphoid cuffing was seen (case 1).

C. Lymphoid aggregates were prominent (case 1).

D. The tumor was composed of hypocellular collagenous matrix with scattered spindle cells and dystrophic calcifications (case 1).

E. A infiltrative proliferation of spindle cells separates the muscularis propria into pieces and results in a patchy pattern (case 2).

F. Spindle cells show immunoreactivity for vimentin (case 1).

\section{Discussion}

CFTs are rare, benign mesenchymal tumors and only twenty cases have been reported confined to the stomach. Most tumors were incidental findings at autopsy or during surgery for other purpose. Contrasting with CFTs of soft tissue, gastric tumors have higher age and smaller tumor size. These facts suggest that gastric CFTs may have different pathogenic pathways from their soft tissue counterpart. Furthermore, most CFTs are located in the stomach body, rare in the antrum and other sites [6,7]. Calcifying fibrous tumors must be included in the differential diagnosis from other gastric mesenchymal neoplasms such as inflammatory fibroid polyp, schwannomas, gastrointestinal stromal tumors (GIST) and inflammatory myofibroblastic tumor (IMT).

Inflammatory Fibroid Polyp: Inflammatory fibroid polyps are located mostly in the antrum. Eosinophildominant inflammatory cell infiltrate is the feature of this tumors [8].

GIST: Psammomatous calcifications and lymphoplasmacytic infiltrates are not features of GISTs and most GISTs express CD117, DOG-1 and CD34 [9].

Gastric Schwannoma: The gastric schwannoma demonstrate strong S100 reactivity $[10,11]$.

IMT: Most of the IMTs demonstrate immunoreactive for both SMA and ALK [12].
In summary, gastric CFTs are distinct clinicopathological body from their soft tissue counterparts. It could be demonstrated by their smaller tumor size, higher age at presentation, and uniformly benign course without local recurrence. The typical morphology and immunohistochemical patterns of CFTs will help to distinguish them from GIST and other spindle cell lesions of the stomach.

\section{References}

1. Rosenthal NS, Abdul Karim FW (1988) Childhood fibrous tumor with psammoma bodies. Clinicopathologic features in two cases. Arch Pathol Lab Med 112: 798-800.

2. Nascimento AF, Ruiz R, Hornick JL (2002) Calcifying fibrous "pseudotumor": clinicopathologic study of 15 cases and analysis of its relationship to inflammatory myofibroblastic tumor. Int J Surg Pathol 10: $189-196$.

3. Puccio F, Solazzo M, Marciano P, Benzi F (2001) Laparoscopic resection of calcifying fibrous pseudotumor of the gastric wall: a unique case report. Surg Endosc 15: 1227.

4. Elpek GO, Kupesiz GY, Ogus M (2006) Incidental calcifying fibrous tumor of the stomach presenting as a polyp. Pathol Int 56: 227-231.

5. Agaimy A, Bihl MP, Tornillo L, Wunsch PH, Hartmann A, et al. (2010) Calcifying fibrous tumor of the stomach: clinicopathologic and molecular study of seven cases with literature review and reappraisal of histogenesis. Am J Surg Pathol 34: 271-278.

6. Agaimy A, Bihl MP, Tornillo L, Wünsch PH, Hartmann A, et al. (2010) Calcifying fibrous tumor of the stomach: clinicopathologic and molecular study of seven cases with literature review and reappraisal of histogenesis. Am J Surg Pathol 34: 271-278. 
7. Delbecque K, Legrand M, Boniver J, Lauwers GY, De Leval L, et al. (2004) Calcifying fibrous tumour of the gastric wall. Histopathology 44: 399400.

8. Kolodziejczyk P, Yao T, Tsuneyoshi M (1993) Inflammatory fibroid polyp of the stomach: a special reference to an immunohistochemical profile of 42 cases. Am J Surg Pathol 17: 1159-1168.

9. Agaimy A, Wunsch PH, Hofstaedter F, Blaszyk H, Rummele P, et al. (2007) Minute gastric sclerosing stromal tumors (GIST tumorlets) are common in adults and frequently show c-KIT mutations. Am J Surg Pathol 31(1): 113-120.

\section{ISSN: 2574-1241}

DOI: $10.26717 / B J S T R .2018 .12 .002210$

Wei Zhao. Biomed J Sci \& Tech Res

(C) (i) This work is licensed under Creative

Submission Link: https://biomedres.us/submit-manuscript.php
10. Daimaru Y, Kido H, Hashimoto H, Enjoji M (1988) Benign schwannoma of the gastrointestinal tract: a clinicopathologic and immunohistochemical study. Hum Pathol 19: 257-264.

11. Daimaru Y, Kido H, Hashimoto H (1988) Benign schwannoma of the gastrointestinal tract: a clinicopathologic and immunohistochemical study. Hum Pathol 19: 257-264.

12. Shi H, Wei L, Sun L, Guo A (2010) Primary gastric inflammatory myofibroblastic tumor: a clinicopathologic and immunohistochemical study of 5 cases. Pathol Res Pract 206: 287-291.

$\begin{array}{ll}\text { BIOMEDICAL } & \text { Assets of Publishing with us } \\ \text { RESEARCHES } & \text { - Global archiving of articles } \\ \text { - Immediate, unrestricted online access }\end{array}$

